\title{
Müzik ve Disleksi: Disleksi Tanısı Alan Öğrencilerin Okuma Düzeylerinin Geliştirilmesinde Müzik Eğitiminin Kullanılması*
}

\author{
Music and Dyslexia: Using Music Education To Improve The Reading Levels Of Students Who Are \\ Diagnosed With Dyslexia
}

\author{
Seda Altunbaş Yavuz ${ }^{* *}$ - Beyzanur Aktaş ${ }^{* * *}$
}

\begin{abstract}
Many methods are applied to improve reading and reading comprehension levels of students with reading difficulties. One of these methods is a musical-rhythmic intervention program based on Kodaly and Orff approaches. When the literature is examined, it is seen that dyslexic children who have undergone musicalrhythmic studies similar to Kodaly and Orff approaches have a good level of word recognition, word interpretation, reading comprehension, and self-expression skills. In this study, musical-rhythmic applications based on Kodaly and Orff pedagogy which provide more active and effective use of reading and reading comprehension processes done in the left hemisphere are included. These applications were supported by paired and rhythmic reading exercises where the student could follow the lyrics on the paper. In this respect, it is similar to the paired reading technique, which is a fluent reading technique. The study is action research within the scope of the qualitative research method. In the study where the criterion sampling method, a purposeful sampling method, was used, three students who had reading difficulty were identified, and reading and reading comprehension levels of students were determined by False Analysis Inventory in 2019 years. Then, TIMI Multiple Intelligence Inventory was applied to these students and a third-grade student who had a dominant musical intelligence was selected. In this way, the musical-rhythmic intervention program selected in accordance with the individual characteristics of the student was made compatible with the Individualized Education Program (IEP). The eight weeks of music education was completed in a total of 24 hours. At the end of the training, it was observed that the dyslexic student's reading and reading comprehension level was increased by applying the False Analysis Inventory again; it was determined that the student's level of word recognition and comprehension increased from "anxiety level" to "instruction level".
\end{abstract}

Structured Abstract: Introduction Reading is an active and interactive process, which requires an intellectual effort and interpretation, where symbols are transformed into sound and meaning (Akyol, 2010; Coltheart, 2005; Sever, 2004). Studies show that reading is an event that occurs in the mind. According to these studies

\footnotetext{
* Bu makale İNCSOS Üsküp (27-30.06.2019)’te sunulan sözlü bildirinin makale formatında hazırlanmış halidir.

** Dr. Öğr. Üyesi, Erzincan Binali Yıldırım Üniversitesi, Eğitim Fakültesi, Temel Eğitim Bölümü Asst. Prof. Dr., Erzincan Binali Ylldırım University, Faculty of Education, Basic Education Department ORCID 0000-0001-5316-6053 seda_a85@hotmail.com

*** Yüksek Lisans Öğrencisi, Erzincan Binali Yıldırım Üniversitesi, Sosyal Bilimler Enstitüsü, Temel Eğitim Bölümü M.A. Student, Erzincan Binali Ylldırım University, Institute of Social Sciences, Basic Education Department ORCID 0000-0003-4232-4997 nurbeyzagg@gmail.com

Cite as/ Atıf: Altunbaş Yavuz, S. \& Aktaş, B. (2020). Müzik ve disleksi: disleksi tanısı alan öğrencilerin okuma düzeylerinin geliştirilmesinde müzik eğitiminin kullanılması. Turkish Studies - Education, 15(3), 1485-1498. https://dx.doi.org/10.29228/TurkishStudies.39431

Received/Geliş: 22 October/Ekim 2019

Accepted/Kabul: 01 May/Ay 2020

Copyright (C) INTAC LTD, Turkey 
explaining reading with cognitive theory, reading refers to a process that starts with the eye tracing the shape and that is interpreted by passing through various stages in the brain (Tracey and Morrow, 2006). Some children have difficulties in learning to read for reasons that are not fully understood despite adequate intelligence and appropriate learning environments (World Federation of Neurology, 1968). In the literature, this condition is called dyslexia.

When literature is examined, it is seen that there is a relationship between music education given to dyslexic children and their literacy skills. However, although these studies suggest that music education can help reading skills, there is little supportive evidence (Overy, 2003). It was suggested in previously conducted studies that there was a relationship between reading skills and music education, but definitive evidence that the improvement in reading skills stemmed from music education could not be reached.

In this study, musical-rhythmic applications based on Kodaly and Orff pedagogy which provides a more active and effective use of reading and reading comprehension processes done. These applications were supported by paired and rhythmic reading exercises where the student could follow the lyrics on the paper.

In this study, an answer to the question "What is the effect of musical-rhythmic interventions on improving the reading and reading comprehension levels of dyslexic students?" was sought.

Method: The study is an action research within the scope of qualitative research method. Action research is a research design applied by the practitioner herself or another researcher, aiming to determine the measures to be taken to improve the current situation (Creswell, 2012; Yildirim \& Simsek, 2011).

In this study, the criterion sampling method, which is a purposeful, was used. According to the criterion sampling method, criteria are determined in advance for the situation that is planned to be studied and all the situations that meet these criteria are studied (Yildirim \& Simsek, 2011, p. 112). In order to create the study group, three students who had reading difficulty were identified, and reading and reading comprehension levels of students were determined by False Analysis Inventory. Then, TIMI Multiple Intelligence Inventory was applied to these students and a third-grade student who had a dominant musical intelligence was selected. In this way, the musical-rhythmic intervention program selected in accordance with the individual characteristics of the student was made compatible with the Individualized Education Program (IEP). At the end of the first grade, it was noticed by the teacher and his/her parents that although the student whose intelligence was in normal limits, he fell behind his peers, and thanks to the school counselor's guidance and direction to the counseling and research center, he was diagnosed with dyslexia in the second grade.

In addition, he has been receiving training at a special education and rehabilitation center for one year. The classroom teacher was given a student observation form and interviewed several times about her observations and opinions about the student. His supportive education teacher and his teacher at the special education and rehabilitation center were given student observation forms and interviewed several times about their observations and opinions about the student. When the student's behaviors were observed, it was seen by the parents and teachers that the student had difficulty in communicating with his peers and teachers, and introvertedness and shyness problems. His teachers mentioned that although he was willing to participate in social activities, he did not speak much and was afraid to express himself. His classroom teacher stated that he had the same text read by everyone, and had the student read the text at the end, and he did repetitive reading until his turn came and was able to read more candidly. A form was applied to determine how the student viewed himself, and his interest, wishes, and expectations were discussed with the student. The student, who was interested in musical activities and musical instruments, prefers to listen to music in his free time. In addition, the False Analysis Inventory was applied to determine his level of reading and the types of errors he frequently made. The student, who often made reading errors during reading, had difficulties in understanding the text he read. However, the student did not have any visual, hearing and speaking problems.

Result and discussion: An application was made to determine the effect of musical-rhythmic interventions on the elimination of reading difficulties of a third-grade primary school student diagnosed with dyslexia. Before music education, the student was made to read the texts in Turkish textbooks. In the meantime, the researchers identified the frequent reading errors made by the student. Students' levels of word recognition and comprehension were determined using the "False Analysis Inventory". Then, the literature was investigated to find the type of method that should be followed for this student, and it was decided to apply for a music education program. During the study, one of the researchers conducted one-to-one activities with the student and had the opportunity to closely monitor the student throughout the process. As a result of the application, it

Turkish Studies - Education, 15(3) 
was seen that repetitive and paired reading of the song texts in the music education program was effective in decreasing the errors of reading aloud and increasing the level of reading comprehension.

The student, who read texts incorrectly and very slowly by doing head movements and following with fingers at the beginning of the study, read a text of 156 words with 20 errors in 11 minutes and 19 seconds. At the end of the music education of 24 hours; the student was able to read a text of 163 words with 8 errors in 3 minutes 48 seconds. At the end of music education, it was seen that the student's ability to recognize and interpret words increased. According to the results of the False Analysis Inventory, the student who was in the 'Anxiety Level' in terms of word recognition and reading comprehension at the beginning of the application reached the 'Instruction Level' in terms of word recognition and reading comprehension at the end of the application.

In the studies conducted to eliminate reading difficulties, the fact that the training activities are conducted with one child out of the classroom in isolation from the others brings along some risks in the study (Reid, 2003). Because it raises the question of whether the progress seen in the reading level of the student is the result of the method carried out during the application or the result of one-to-one attention with the student. However, when we look at this study in which the music education program was applied and the studies in which the dyslexia is eliminated with music, it seems like a suitable practice to be applied in the classroom with peers. It will be effective to raise awareness of class teachers or music teachers about the effect of music education on the elimination of reading difficulties. It will be possible to use fluent reading techniques such as paired reading and repetitive reading by following the texts of songs sung in the music lessons where children with and without reading difficulties are together; and this will prevent the implementation of the intervention plan in isolation from other children.

Another important issue is the student's motivation to read. Researchers point out that motivated children read books more frequently and consequently fluency in reading is achieved (Wang and Guthrie, 2004; Guthrie, Wigfield, Metsala and Cox, 1999). Since this study was conducted by taking into consideration the student's interest, wishes, and skills; his motivation for vocalizing the song texts turned into a motivation generalizable also for normal texts at the end of the educational process. In this study, it was observed that the motivation of the student to read increased thanks to this technique, and therefore his amount of reading increased. It was observed in the study that as the student's reading errors decreased and he started to read fluently, his comprehension level increased.

Keywords: Reading program, Dyslexia, Musical intelligent, TIMI multiple intelligence inventory, Action research.

Öz: Okuma güçlüğü yaşayan öğrencilerin okuma ve okuduğunu anlama düzeylerini iyileştirmek için birçok yöntem uygulanmaktadır. Bu yöntemlerden biri de Kodaly ve Orff yaklaşımına dayanan müziksel-ritmik müdahale programıdır. Alan yazın incelendiğinde Kodaly ve Orff yaklaşımına benzer müziksel-ritmik çalışmalar yapılan disleksik çocukların kelime tanıma, kelimeyi anlamlandırma, okuduğunu anlama ve kendini ifade etme becerilerinin iyi düzeyde olduğu görülmektedir. Bu çalışmada sol hemisferde işlenen okuma ve okuduğunu anlama süreçlerinin daha aktif ve etkin kullanımını sağlayan Kodaly ve Orff pedagojisi temelindeki müziksel-ritmik çalışmalara yer verilmiştir. Bu çalışmalar öğrencinin şarkı sözlerini kâğıt üzerinden takip edebileceği eşli ve ritmik okuma çalışmalarıyla desteklenmiştir. Bu yönüyle akıcı okuma tekniklerinden eşli okuma tekniği ile benzerlik göstermektedir. Çalışma, nitel araştırma yöntemi kapsamında bir eylem araştırmasıdır. Amaçlı örnekleme yöntemlerinden ölçüt örnekleme yönteminin kullanıldığı, 2019 yılında uygulanılan çalışmada, okuma güçlüğü yaşayan üç öğrenci belirlenip Yanlış Analizi Envanteri uygulanarak ögrencilerin okuma ve anlama düzeyi tespit edilmiştir. Daha sonra bu öğrencilere TIMI Çoklu Zekâ Envanteri uygulanarak, müziksel zekâsı baskın olan bir 3.sınıf öğrencisi seçilmiştir. Böylelikle öğrencinin bireysel özellikleri de dikkate alınarak seçilen müziksel-ritmik müdahale programının Bireyselleştirilmiş Eğitim Programına (BEP) uygunluğu sağlanmıştır. Sekiz haftayı kapsayan müzik eğitimi toplam 24 ders saatinde tamamlanmıştır. Eğitim sonunda Yanlış Analizi Envanteri tekrar uygulanarak disleksik öğrencinin okuma ve okuduğunu anlama düzeyinde artış olduğu gözlemlenmiş; öğrencinin kelime tanıma ve anlama düzeyinin “endişe düzeyi”nden "öğretim düzeyi”ne çıktığı tespit edilmiştir.

Anahtar Kelimeler: Okuma-yazma öğretimi, Okuma güçlüğü, Müziksel zekâ, TIMI çoklu zekâ envanteri, Eylem araştırması. 


\section{Giriş}

Okuma; sembollerin ağız yoluyla sese ve beyin yoluyla anlama dönüştüğü, bilişsel ve anlamlandırmayı gerektiren bir süreç olup, aktif ve etkileşimli bir şekilde devam eden bir beceri alanıdır. (Akyol, 2010; Coltheart, 2005; Sever, 2004). Yapılan çalışmalar okumanın zihinde gerçekleşen bir olay olduğunu göstermektedir. Okumayı bilişsel teori ile açıklayan bu çalışmalara göre okuma; gözün şekli takip etmesi ile başlayıp beyinde çeşitli aşamalardan geçerek anlamlandırılan bir süreci ifade etmektedir. (Tracey ve Morrow, 2006). Okuma boyunca, yazılar zihinde kavramlara çevrilir, anlamlandırılır ve böylece beyinde yapılandırılır (Güneş, 2007). Bu yapılandırma sürecinde meydana gelebilecek herhangi bir aksaklık doğru bir okumanın olmasının önüne geçmektedir. Çocuklardan bazıları, zekâ ve diğer değişkenler bakımından herhangi bir sorun teşkil etmemesine rağmen, nedeni tam olarak bilinmeyen sebeplerle okumayı öğrenmede zorluk çekmektedirler (World Federation of Neurology, 1968). Çocukların yaşadığı ve nedeni belli olmayan bu duruma okuma güçlüğü (disleksi) denilmektedir.

DSM-IV (Ruhsal Bozuklukların Tanısal ve Sayımsal El Kitabı) Disleksi’yi; “"zekası normal ya da normalin üstünde olan bireylerin, standart testlerde, yaş, zeka düzeyi ve aldığı eğitim göz önünde bulundurulduğunda, okuma, matematik ve yazılı anlatımın beklenenin önemli ölçüde altında olmasıyla tanısı konulan bir bozukluktur." şeklinde tanımlamaktadır. Bu sebeple disleksinin erken tanı ve tedavisi önem arz etmektedir. Bazı çalışmalar da disleksiyi ve nedenlerini farklı açılardan incelemiştir (Razon, 1976; Vanl1, 1988). Disleksinin çalışma belleğiyle olan ilişkisi incelendiğinde disleksinin nedenleri daha net ortaya çıkmaktadır.

Çalışma belleği, kısa süreli belleğin aktif ve dinamik durumu olarak ortaya koyulmuştur (Baddeley ve Hitch, 1974). Buna göre çalışma belleği karmaşık bilişsel aktiviteleri koordine ve entegre etmektedir. Çalışma belleğinin bilişsel karmaşayı koordine ve entegresinde; GörselMekansal kopyalama, Fonolojik döngü ve Merkezi yönetici önemli rol oynamaktadır. Görsel mekânsal algılama, üç boyutlu bir şekil yapılandırma ve şekil kopyalama gibi işlemler gerektirir. Fonolojik döngü; fonolojik süreçle ile ilgili olup, fonolojik bellek ve artikülasyondan oluşan bir döngüdür. (Tercan, Kesikçi Ergin ve Amado, 2012). İşitsel bilgiler otomatik olarak fonolojik belleğe dönüştürülür. Artikülasyon döngüsü de kelimelerin tekrarlanarak silinmesinin engelleyen bir "içsel ses" görevi yapar. Bu bellek kapasitesinin sınırlı olmasından dolayı disleksik çocukların okuma sürecinde sorun yaşadıklarına yönelik veriler bulunmaktadır. (Snowling, 1981; Brady, Shankwieler, ve Mann, 1983; Snowling, Gaulandris, Bowlby ve Howell, 1986).

Müzik ve dil becerileri pek çok yönden ortak özellikler sergilemektedir. Bunlar:

- Öğrenme gerektiren unsurlardır.

- İnsan yapımı kültüre bağlı seslerdir.

- Zamanla ortaya çıkan karmaşık-yapılandırılmış malzemelerdir.

- Küçük birimlerin daha büyük birimlerle birleştirilmesi sonucu oluşur.

- Kurallar ve sözdizimimi vardır.

- Doğası gereği sosyal, iletişimsel ve duygusal unsurlar barındırır (Huss, 2011).

Disleksik çocukların işitsel becerilerin ve okuryazarlık becerilerinin iyileşmesinde müzik eğitiminin etkili olduğuna dair birçok çalışma bulunmaktadır. (Tallal ve Gaab, 2006) Bu araştırmalarda müzik eğitimi ile okuryazarlık becerilerinin gelişimi arasındaki olası ilişkileri gösteren modellere rastlanmaktadır (Overy, 2003).

6-9 yaş arası çocuklarda müzik eğitimi süresi, okuduğunu anlama performansı - yaş kontrolü, SES, işitsel algı, IQ, okuma miktarı, kelime kod çözme becerileri ile ilişkilendirilmiştir. (Corrigall ve Trainor, 2011) Benzer bir çalışmada disleksik 8-12 yaşları arasındaki çocuklar 18 saatlik müzik 
temelli bir müdahaleye katılmıştır. Eğitim sonrasında çocukların konuşma algısı, işitsel dikkati, kelime telaffuzu, 1 dakika içinde okuma hızı, bir fonem işleme görevinde doğruluk gibi becerilerinde gelişme olduğu gözlemlenmiştir (Habib ve diğerleri, 2016).

Başka bir araştırmada da 8 yaşındaki çocuklar 6 aylık müzik eğitimi ve 6 aylık resim eğitimi olan rastgele iki müdahaleden birine atanmışlardır. Müzik eğitimi ritim, melodi uyumu vb. eğitimlerden; resim eğitimi ise görsel uzamsal performansa odaklanan eğitimlerden oluşmaktadır. Eğitimler sonunda sadece müzik eğitiminin kelime okuma görevinde performansı kolaylaştırdığ 1 görülmüştür (Moreno ve diğerleri, 2008). Buna benzer başka bir araştırmada müzik veya resim eğitimine randomize edilmiş 8-11 yaş arası disleksik çocukların 7 ay süren eğitim sonundaki gelişmeleri gözlemlenmiștir. Yapılan gözlemler sonucunda müzik grubunun sözlü çalıșma hafizasının, fonemik harmanlamanın(seslerden kelimelere), kelime okuma ve metin okuma doğruluğunun daha da geliştiği görülürken; resim grubunun, algısal görsel uzay-uzamsal akıl yürütmede geliştiği görülmüştür (Flaugnacco ve diğerleri, 2015).

Bireyin bilişsel süreçlerinin normal seyrinde olması ve bunun bir göstergesi olan akademik başarı, sadece ders başarısını değil, yaşamın tüm alanlarını etkileyen önemli bir durumdur (Kurdoğlu, 2005). Yaşına uygun performans göstermesi, okul yaşındaki çocuktan beklenen bir olgudur. İlkokula başlayan bir öğrenci akademik sürece, okuma ve yazma öğrenmeyle giriș yapar. Dolasıyla bireydeki okuma güçlüğünün ilk fark edildiği dönem ilkokul dönemleridir. Çocuk psikiyatri bölümlerine yapılan başvuruların büyük bir bölümünü de ders başarısızlığı ya da okula uyum sorunları oluşturmaktadır (Karaman ve diğerleri, 2012). Başarı ya da başarısızlık tek bir nedene bağlı olmamakla birlikte zihinsel yetersizlikler, aile içi problemler, motivasyon eksikliği, öğretmen, okul gibi etkenler, bireyin akademik başarısında belirleyici olmaktadır (Korkmazlar, 1994). Bu nedenlerle ortaya çıkan öğrenme sorunlarının dışında kalan özel bir durum ise "Disleksi"dir.

Alan yazın incelendiğinde disleksik çocukların aldıkları müzik eğitimleri ile okuryazarlık arasında bir ilişkinin olduğu farkedilmektedir. Ancak bu araştırmalar müzik eğitimin okuma becerilerine faydası olabileceğini varsaysa da destekleyici kanıtlar azdır (Overy, 2003). Daha önce yapılan çalışmalarda müzik eğitimi ile okuma becerisi arasında bir ilişkinin olduğu açıklanmış, ancak okuma becerisindeki gelişmenin müzik eğitimden kaynaklandığına dair kesin delillere ulaşılamamıştır. Müzik ve disleksi ile ilgili yapılan önceki araştırmalar nedensel değil, korelasyonel araştırmalar olması yönüyle sınırlılık göstermektedir. Bu çalışmada ise araştırma problemiyle ilgili çoklu kanıtlara ulaşılarak ve derinlemesine incelenerek nedensel sonuçlara ulaşılmaya çalışılmıştır.

$\mathrm{Bu}$ araştırmada sol hemisferde işlenen okuma ve okuduğunu anlama süreçlerinin daha aktif ve etkin kullanımını sağlayan Kodaly ve Orff pedagojisine dayanan müziksel-ritmik çalışmalara yer verilmiştir. Bu çalışmalar öğrencinin şarkı sözlerini kâğıt üzerinden takip edebileceği eşli ve ritmik okuma çalışmalarıyla desteklenmiştir. Bu yönüyle akıcı okuma tekniklerinden eşli okuma tekniği ile benzerlik göstermektedir.

Bu çalışmada "Disleksik öğrencilerin okuma ve okuduğunu anlama düzeylerinin iyileştirilmesinde müziksel-ritmik müdahalelerin etkisi nedir?" sorusuna cevap aranmaya çalışılmıştır.

\section{Yöntem}

\section{Araștırmanın Modeli}

Çalışma, nitel araştırma yöntemi kapsamında bir eylem araştırmasıdır. Eylem araştırması, araştırmacının kendisi ya da başka biri tarafından uygulanan, olan durumu daha iyihale getirmek üzere alınacak önlemleri tespit etmeyi hedefleyen bir araştırma desenidir (Yıldırım ve Şimşek, 2011; Creswell, 2012). Eylem araştırması, problem tanılanmasında ve çözümünde yapılanların yetersiz kalması durumunda yeniden çözüm üreten, yaparak ve yaşayarak öğrenmeyi öngören bir modeldir (O’Brien, 2003). 


\section{Çalışma Grubu}

Çalışmada amaçlı örnekleme yöntemlerinden biri olan ölçüt örnekleme yöntemi kullanılmıştır. $\mathrm{Bu}$ örnekleme yöntemi ile, çalışılması planlanan durumla ilgili önceden ölçüt belirlenmesi ve bu ölçütleri sağlayan bütün durumların çalışılması söz konusudur (Yıldırım ve Şimşek, 2011). Araştırmanın çalışma grubunu belirlemek için okuma güçlügü yaşayan üç öğrenci belirlenmiş, Yanlış Analizi Envanteri uygulanmış ve öğrencilerin okuma/anlama düzeyleri tespit edilmiştir. Bir sonraki süreçte öğrencilere TIMI Çoklu Zekâ Envanteri uygulanarak, müziksel zekâsı baskın olan bir 3.sınıf öğrencisi seçilmiştir. Böylelikle öğrencinin bireysel özellikleri de dikkate alınarak seçilen müziksel-ritmik müdahale programının Bireyselleştirilmiş Eğitim Programına (BEP) uygunluğu sağlanmıştır. 1.sınıfın sonunda öğretmeni ve ebeveynleri tarafından öğrencinin normal zekaya sahip olmasına rağmen akranlarından geri kaldığı fark edilmiş ve rehber öğretmenin rehberlik ve araştırma merkezine yönlendirmesi sonucunda 2.sınıfta disleksi tanısı konulmuştur. Öğrencinin annesi ev hanımı, babası tır şoförüdür. Öğrencinin kardeşinin ise ağır düzey zihinsel engel tanısı bulunmaktadır. Öğrenci okul derslerinin dışında haftada iki kez destek eğitim odasında birebir ders almaktadır. Ayrıca bir senedir özel eğitim ve rehabilitasyon merkezinde de eğitim almaya devam etmektedir. Sınıf öğretmenine öğrenci gözlem formu verilerek öğrenci ile ilgili gözlem ve görüşleri hakkında birkaç kez görüşülmüştür. Destek eğitim öğretmeni ile özel eğitim ve rehabilitasyon merkezindeki öğretmenine de öğrenci gözlem formu verilerek öğrenci hakkında detaylı bilgi alınmıştır. Aile ve öğretmenlerin ortak görüşü ile öğrenci davranışları gözlemlendiğinde öğrencide akranlarıyla ve öğretmeniyle iletişim kurmakta güçlük, içe kapanıklık ve çekingenlik olduğu görülmüştür. Öğretmenleri sosyal etkinliklere katılmaya istekli olmakla birlikte çok fazla konuşmadığını ve kendini ifade etmekten çekindiğini dile getirmiştir. Sınıf öğretmeni sınıf içerisinde okuma yaptırırken aynı metni herkese tek tek okuttuğu, öğrenciyi en son okuttuğunu dile getirmiş, sıra kendisine gelene kadar tekrarlı okuma yapmış olduğunu ve daha çekinmeden okuyabildiğini söylemiştir. Öğrencinin kendisini nasıl gördügünü belirlemek için de bir form uygulanmış ve öğrenci ile ilgi, istek ve beklentileri üzerine konuşulmuştur. Müziksel faaliyetlere ve müzik enstrümanlarına ilgi duyan öğrenci, serbest vakitlerinde müzik dinlemeyi tercih etmektedir. Ayrıca Yanlış Analizi Envanteri uygulanarak okuma düzeyi ve sıklıkla yaptı̆ğ hata türleri tespit edilmiştir. Okuma sırasında sıklıkla okuma hataları yapan öğrenci, okuduğu metni anlamada da güçlükler yaşamaktadır. Bunlarla birlikte öğrencin görme, işitme ve konuşma gibi herhangi bir sağlık problemi bulunmamaktadır.

\section{Geçerlik ve Güvenirlik}

Nitel desenli araştırmalarda geçerlik ve güvenirliğin sağlanabilmesi için inandırıcılığın sağlanmış olması gerekmektedir (Guba ve Lincoln, 1982). Bunun gerçekleşebilmesi için gerekli bazı ölçütler şunlardır: inandırıcı olma, güvenilir olma, onaylanabilirlik ve aktarılabilirlik. Bulguların doğruluğu bu stratejilerin en az birinin sağlanması ile kontrol edilebilir. (Creswell, 2015). İnandırıcı olma konusunda alınabilecek önlemlerden birisi araştırma konusu hakkında uzman kişilerden, araştırmanın birçok boyutuyla değerlendirmesinin istenmesidir. (Başkale, 2016). Bu yöntem uzman incelemesi olarak adlandırılmaktadır (Creswell, 2015). Bu çalı̧̧mada da uzman incelemesi ve görüşlerine başvurulmuş ayrıca verilerin geçerliğini ve güvenirliğini teyit etmek, araştırmanın niteliğini artırmak ve geniş bir bakış açısı sağlamak için çeşitli veri toplama tekniğinden yararlanılmıştır (Yıldırım ve Şimşek, 2016). Bu amaçla araştırma sürecinde kullanılan veri toplama araçları "Yanlış Analizi Envanteri, TIMI Çoklu Zeka Envanteri, Okuma Metinleri, Ses Kayıtları ve Araştırmacı Günlükleri” başlıkları altında açıklanmıştır.

\section{Veri Toplama Araçları}

Bu araştırmada veri toplamı araçları olarak "Yanlış Analizi Envanteri", "TIMI Çoklu Zeka Envanteri”, "Okuma Metinleri”, "Ses Kayıtları” ve "Araştırmacı Günlükleri” kullanılmıştır. 
Yanlış Analizi Envanteri: Envanter, "kelime yanlışları ve işaretleri", "kelime tanıma düzeyi ve yüzdeliğini belirleme kılavuzu", "soru ölçeği” ve "anlama düzeyi” olmak üzere dört bölümden oluşmaktadır (Akyol, 2016). Bu envanter ile okuma ve anlama düzeylerinde üç seviye belirlenmektedir. Çocukların, başka birinin yardımına gerek olmadan, seviyesine uygun okuması ve anlaması, çocuğun serbest düzeyde olduğunu; başka birinin yardımı ile seviyesine uygun okuyup anlaması, çocuğun öğretim düzeyinde olduğunu ve çocukların metin üzerinde çok fazla okuma hatası yapması veya okuduğunun çok azını anlaması ise çocuğun endişe düzeyinde olduğunu göstermektedir.

$\mathrm{Bu}$ düzeylerin belirlenmesi aşamasında Akyol'un (2016) Ekwall ve Shanker'den (1988) uyarladığı okuma düzeyi ve yüzdelikleri ölçüt olarak kullanılmıştır. Bu düzeyler ve yüzdelikleri aşağıdaki tabloda sayısal olarak gösterilmiştir.

Tablo 1: Okuma Düzeyleri ve Yüzdelikleri

\begin{tabular}{lll}
\hline Okuma Düzeyleri & $\begin{array}{l}\text { Kelime } \\
\text { Tanıma }\end{array}$ & Anlama \\
\hline Serbest Okuma Düzeyi & $\% 99+$ & $\% 90+$ \\
\hline Öğretim Düzeyi & $\% 95+$ & $\% 75+$ \\
\hline Endişe Düzeyi & $\% 90-$ & $\% 50-$ \\
\hline
\end{tabular}

Okuduğunu anlamayı belirlemede sorular iki gruba ayrılmaktadır. Bunlar basit anlama ve derin anlama dayalı sorular olmaktadır. Soru düzeylerinin belirlenmesi ve cevapların puanlandırılmasında uzman görüşüne başvurulmuştur. Basit anlama dayalı sorular puanlanırken; doğru olarak verilmiş cevaplara "2" puan; yarısı doğru verilmiş cevaplara "1" puan ve yanlış cevaplara ise "0" puan verilmiştir. Aynı şekilde derinlemesine anlama dayalı sorular puanlanırken; doğru olarak verilmiş cevaplara "3" puan; cevabın yarısından fazlasını doğru olarak verilmiş cevaplara "2" puan; yarısı doğru verilmiş cevaplara " 1 " puan ve yanlış cevaplara ise " 0 " puan verilerek hesaplama yapılmıştır (Akyol, 2016).

Okuma ve okuduğunu anlamaya yönelik uygulanan Yanlış Analizi Envanteri, müzik eğitiminden önce öğrenci düzeyini tespit etmek ve müzik eğitiminden sonra öğrencinin okuma düzeyini tespit etmek üzere ön test-son test şeklinde uygulanmıştır.

Teele Çoklu Zeka Envanteri (TIMI): TIMI testi Sue Teele tarafindan 1992 yılında okul öncesi, ilköğretim, lise ve üniversitede bireylerin baskın zeka alanlarını araştırmak için oluşturulmuştur. Amerika'da okul öncesi dönemden üniversiteye kadar 650'den fazla okulda kullanılmaktadır. Teele'nin çalışması sonucunda "görsel-uzamsal, müziksel-ritmik, kinestetikbedensel, sözel-dilsel, kişisel-içsel, sosyal-dışa dönük, doğa-çevresel, aritmetik-matematik zeka alanları" gibi baskın zeka alanları oluşturulmuştur. (Teele, 1997). Öğrencinin baskın olduğu zekayı belirlemek için uygulanan TIMI Çoklu Zeka Envanteri'nde her sayfada iki farklı panda resmi bulunmaktadır. Öğrenciye her sayfada "Sen bu pandanın yerinde olsan hangisini yapmak isterdin?" diye sorulur. Bu şekilde 28 sayfada 56 panda resmi bulunmaktadır. Öğrencinin tercihlerine göre değerlendirme formu doldurulur ve baskın olduğu zeka alanları belirlenir. Özellikle okuma yazma bilmeyen ya da okuma yazma konusunda güçlük yaşayan öğrenciler için kullanışlıdır. Çünkü okumada hataları olan bireylere uygulanan yazılı envanterler hatalı sonuçlar vermektedir. $\mathrm{Bu}$ envanter resimlerden oluştuğu için okuma güçlüğü olan öğrenciler için geçerli ve güvenilirdir.

Okuma Metinleri: Öğrencinin, okuma ve anlama düzeyini tespit etmek için Milli Eğitim Bakanlığı ve Talim Terbiye Kurulu Başkanlığı onaylı Türkçe ders kitaplarından yararlanılmıştır. Yanlış analizi envanterinde kullanılması için seçilen okuma parçaları, çocukların düzeyine uygun seçilmelidir. Sınıf düzeyine göre metinlerdeki kelime sayıları, birinci ve ikinci sınıflar; 25-100 kelime arası; üçüncü ve dördüncü sınıflar; 100-200 kelime arası; beşinci ve altıncı sınıflar; 200-300 kelime arası ve yedinci ve sekizinci sınıflar ise; 300-350 kelime arası olabilir (Akyol, 2011: 98). 
Öğrenci 3.sınıfta öğrenim gördüğünden okuma ve okuduğunu anlama düzeyinin tespiti için 3.sınıf, 2. Sınıf ve 1. Sınıf metinleri sırasıyla okutulmuştur. Öğrencinin seviyesi 2. Sınıf olarak belirlendiğinden Türkçe 2 ders kitabında yer alan 156 kelimden oluşan "Uğur Böceğim" metni seçilmiş ve uzman görüşü alınmıştır.

Eğitim sürecinde ise müzik eğitimi sırasında öğrencinin ilgi ve istekleri de dikkate alınarak seçilen şarkıların sözleri yazılıp müzik eşliğinde ve ritimle okunmuştur. Tanıtılan ritim enstrümanları içerisinden öğrenci darbukayı seçmiştir. Eğitim sırasında ilk önce müzik çalardan belirlenen şarkı birkaç kez dinlenilmiş, daha sonra şarkı metninden takip ederek önce uygulayıcıyla eşli okuma yapılmış, daha sonra öğrenci kendi okumuş, en son hem ritim tutup hem okumuştur.

Ses Kayıtları: Öğrencinin, okuma ve okuduğunu anlama düzeyinin belirlenmesinde ve müzik eğitiminin yapıldığı çalışma programı süresince ses kayıtları alınarak analiz edilmiştir. Ön test, son test ve ara değerlendirmelerde yapılan okumalar ve müzik eğitimi araştırmacı tarafından kayıt altına alınmıştır. Çalışmanın sonunda bu ses kayıtları arşiv haline getirilerek aile ile paylaşılmıştır.

Araştırmacı Günlükleri: Süreç boyunca yapılan görüşme ve çalışmalar esnasında alınan notlar, verileri kontrol etmek, araştırmanın güçlü ve zayıf yönlerini belirlemek ve olası hataları en aza indirmek adına araştırmacı günlüğüne kaydedilmiştir. Bu notlar uygulamayı yürüten araştırmacı tarafından her hafta bir uzmanla paylaşılmış ve bu notlar üzerinden değerlendirmeler yapılarak bir sonraki adım konusunda kararlar alınmıştır.

Görüssme Formları: Çalışma öncesinde ve sonrasında, öğrenci hakkında bilgi edinebilmek amacıyla öğrencinin öğretmenleriyle, ailesiyle ve akranlarıyla görüşülmüş ve bu görüşme çıktıları kaydedilmiştir.

\section{Veri Analizi}

Araştırmada veriler şu şekilde analiz edilmiştir:

Kelime tanıma düzeyi: Okuma doğruluğu için "doğru okunan kelime sayısı / okunan kelime sayıs1 x 100 = doğru okuma yüzdesi” şeklinde hesaplanmıştır. Hesaplamanın yapılabilmesi için "Yanlış Analiz Envanteri" (Akyol (2016) tarafindan Ekwall ve Shanker'den (1988) uyarlanan) kullanılmıştır.

Anlama Düzeyi: Okuduğunu anlamayı değerlendirmede sorular basit anlama ve derin anlama dayalı sorular olmak üzere iki düzeye ayrılmış ve bu düzeylere göre puanlandırılmıştır (Akyol, 2016).

Baskın Zeka Alanı: Öğrenin TIMI Çoklu Zeka Envanterine verdiği cevaplar doğrultusunda değerlendirme formunda seçtiği her bir resme karşılık gelen zeka alanları puanları toplanarak en çok puan aldığı zeka alanı belirlenmiştir.

\section{Bulgular}

Teele Çoklu Zeka Envanteri (TIMI) sonucunda öğrencinin baskın zeka alanının müzikselritmik zeka alanı olduğu görülmüştür. Bundan dolayı 24 saat sürecek bir müzik eğitimi programı hazırlanmış ve eğitimin başında uygulanan Yanlış Analizi Envanteri eğitimden sonra da uygulanarak bulgular saptanmıştır.

Yanlış Analizi Envanteri kullanılırken öğrencinin sınıf düzeyinin bir altından başlanılmasıması önerildiğinden (Akyol, 2011), çalışmadaki öğrenci ilkokul üçüncü sınıf öğrencisi olmasına rağmen yapılan testler sonucunda okuma seviyesi göz önünde bulundurularak ikinci sınıf metin örnekleri seçilmiştir.

Uygulamanın başında öğrencinin okuma hata türlerini, okuma ve anlama düzeyini belirleyebilmek için uzman görüşü alınarak Milli Eğitim Bakanlığının ders kitabından seçilen "Uğur 
Böceğim” isimli 2.sınıf metni öğrenciye sesli olarak okutulmuş okuma süresi, okuma hataları, hata sayısı ve okuma düzeyi belirlenmiştir. Müzik eğitim programının sonunda aynı metin tekrar okutularak son test çalışması yapılmış ve sonuçları aşağıdaki tabloda karşılaştırılmıştır.

Tablo 2: "Uğur Böceğim” Metni Üzerinden Okuma Hataları ve Düzeyine İlişkin Ön test ve Son Test Sonuçları

\begin{tabular}{|c|c|c|c|c|c|c|c|}
\hline $\begin{array}{l}\text { Sinıf } \\
\text { Düzeyi }\end{array}$ & Metin adı & $\begin{array}{l}\text { Kelime } \\
\text { Sayısı }\end{array}$ & $\begin{array}{l}\text { Yapılan } \\
\text { Testler }\end{array}$ & $\begin{array}{l}\text { Okuma } \\
\text { Süresi }\end{array}$ & Okuma Hataları & $\begin{array}{l}\text { Hata } \\
\text { sayısı }\end{array}$ & $\begin{array}{l}\text { Okuma } \\
\text { Düzeyi }\end{array}$ \\
\hline \multirow{14}{*}{ 2.Sinif } & \multirow{14}{*}{$\begin{array}{c}\text { Uğur } \\
\text { Böceğim }\end{array}$} & \multirow{14}{*}{156} & \multirow{7}{*}{ Ön test } & \multirow{7}{*}{$\begin{array}{c}11 \mathrm{dk} . \\
9 \mathrm{sn} .\end{array}$} & Atlamalar & 2 & \multirow{7}{*}{$\begin{array}{l}\text { Endişe } \\
\text { Düzeyi }\end{array}$} \\
\hline & & & & & Eklemeler & 3 & \\
\hline & & & & & Öğretmen & & \\
\hline & & & & & $\begin{array}{c}\text { Tarafindan Verilen } \\
\text { Kelimeler }\end{array}$ & 3 & \\
\hline & & & & & Tekrarlar & 1 & \\
\hline & & & & & Yanlış Okuma & 11 & \\
\hline & & & & & Toplam & 20 & \\
\hline & & & \multirow{7}{*}{ Son test } & \multirow{7}{*}{$\begin{array}{c}4 \mathrm{dk} .36 \\
\text { sn. }\end{array}$} & Atlamalar & 2 & \multirow{7}{*}{$\begin{array}{l}\text { Öğretim } \\
\text { Düzeyi }\end{array}$} \\
\hline & & & & & Eklemeler & 1 & \\
\hline & & & & & Öğretmen & & \\
\hline & & & & & $\begin{array}{c}\text { Tarafindan Verilen } \\
\text { Kelimeler }\end{array}$ & 1 & \\
\hline & & & & & Tekrarlar & 1 & \\
\hline & & & & & Yanlış Okuma & 3 & \\
\hline & & & & & Toplam & 8 & \\
\hline
\end{tabular}

Yukarıdaki tabloda ön test sonuçları incelendiğinde yanlış okumadan kaynaklı hata türünün daha çok olduğu görülmektedir. "Uğur Böceğim" metni 156 kelimeden oluşmaktadır. Sesli okuma esnasında öğrenci toplam 20 okuma hatası yapmıştır. Öğrenci $\% 90$ oranında kelime tanıma yüzdesine sahiptir ve okuma düzeyi "Endişe Düzeyi”ndedir.

Son test sonuçları incelendiğinde öğrencinin yirmi dört saatlik eşli ve tekrarlı müzik metinleri okuma çalışmaları sonucunda okuma hatalarında ciddi oranda azalma görülmektedir. Toplam hata sayıs1 20'den 8'e düşmüştür. Kkelime tanıma yüzdesi \%90'dan \%95'e çıkan öğrencinin okuma düzeyinin de "Endişe Düzeyi”nden “Öğretim Düzeyi”ne çıktığı görülmektedir.

Öğrencinin anlama düzeyini belirleyebilmek için seçilen "Tavşan ile Kaplumbağa" isimli metin ise 2. Sınıf Milli Eğitim kitabında yer alan bir okuma parçasıdır. Öğrencin belli bir süre içerisinde sessiz okuması sağlanmış ve daha sonra okuduğu metin ile ilgili toplam beş soru sorulmuştur. Bu soruların üçü basit anlamaya, ikisi de derin anlamaya dayalıdır. Öğrencinin sorulan sorulara verdiği cevapların kaydı tutulmuş ve alanda uzman 2 kişi tarafından incelenerek puanlanmıştır. Aynı metin çalışmanın sonunda okutularak aynı sorular sorulmuş ve sonuçlar aşağıdaki tabloda karşılaştırılmıştır.

Tablo 3: "Tavşan ile Kaplumbağa” Metni Üzerinden Okuduğunu Anlamaya Yönelik Ön test ve Son test Sonuçları

\begin{tabular}{cccccccc}
\hline $\begin{array}{c}\text { Sınıf } \\
\text { Düzeyi }\end{array}$ & Metin adı & $\begin{array}{c}\text { Kelime } \\
\text { Sayısı }\end{array}$ & $\begin{array}{c}\text { Yapılan } \\
\text { Testler }\end{array}$ & $\begin{array}{c}\text { Okuma } \\
\text { Süresi }\end{array}$ & $\begin{array}{c}\text { Alınan } \\
\text { Puan }\end{array}$ & $\begin{array}{c}\text { Anlama } \\
\text { Yüzdesi }\end{array}$ & $\begin{array}{c}\text { Okuma } \\
\text { Düzeyi }\end{array}$ \\
\hline \multirow{2}{*}{ 2.Sınıf } & $\begin{array}{c}\text { Tavşan ile } \\
\text { Kaplumbağa }\end{array}$ & \multirow{2}{*}{163} & Ön test & $\begin{array}{c}12 \mathrm{dk} . \\
5 \mathrm{sn} .\end{array}$ & 6 & $\% 46$ & $\begin{array}{c}\text { Endişe } \\
\text { Düzzeyi }\end{array}$ \\
\cline { 5 - 8 } & & Son test & $5 \mathrm{dk} .8 \mathrm{sn}$. & 10 & $\% 76$ & $\begin{array}{c}\text { Öğretim } \\
\text { Düzeyi }\end{array}$ \\
\hline
\end{tabular}


Öğrencinin "Tavşan ile Kaplumbağa" metnine ilişkin verdiği ön test cevapları değerlendirilmiştir. Bu değerlendirmede öğrenci birinci ve üçüncü sorudan 1'er puan, ikinci sorudan 0 puan, dördüncü ve beşinci sorudan 2'şer puan alarak her iki soru türünden toplam 6 puan almıştır. Öğrencinin tüm soruları doğru cevaplaması halinde alması gereken toplam puan ise 13'tür. Buna göre öğrencinin başarı durumu $6 / 13$ olduğundan okuduğunu anlama yüzdesi \%46 olarak bulunmuştur. Buradan öğrencinin metni anlama düzenin "Endişe Düzeyi" olduğu sonucuna varılmıştır.

Müzik eğitiminin ardından yapılan son testte öğrencin belli bir süre içerisinde sessiz okuması sağlanmış ve daha sonra okuduğu metin ile ilgili toplam beş soru sorulmuştur. Bu soruların üçü basit anlamaya, ikisi de derin anlamaya dayalıdır. Öğrencinin sorulan sorulara verdiği cevapların kaydı tutulmuş ve alanda uzman 2 kişi tarafından incelenerek puanlanmıştır. Bu değerlendirmede öğrenci birinci sorudan 2 puan, ikinci ve üçüncü sorudan 1'er puan, dördüncü ve beşinci sorudan 3'er puan alarak her iki soru türünden toplam 10 puan almıştır. Öğrencinin tüm soruları doğru cevaplaması halinde alması gereken toplam puan ise 13'tür. Buna göre öğrencinin başarı durumu 10/13'tür. Yani başarı yüzdesi \%46'dan \%76'ya çıkmıştır. Bu da verilen müzik eğitimi sonunda öğrencinin metni anlama düzeyinin "Eğitim Düzeyi”nden “Öğretim Düzeyi”ne çıktığını göstermektedir.

Öğrencinin çalışma öncesindeki ve çalışma sonrasındaki düzeyini daha doğru değerlendirebilmek için çalışmanın başında verilen "Uğur Böceğim" adlı metin çalışma sonunda tekrar verilerek karşılaştırılmıştır. Ön test ile son test arasında 8 hafta gibi uzun bir süre geçmiş olmasından öğrencinin metindeki kelimeleri hatırlama ihtimali ve dolayısıyla sonucun bu durumdan etkilenme ihtimali düşüktür. Ancak olası riskleri en aza indirgemek için çalışma sonunda sınıf düzeyi aynı olan farklı bir metin seçilerek çalışma öncesindeki metinle karşılaştırılmıştır. Çalışma sonunda verilen 2.Sınıf düzeyindeki "Selim'in Çürük Dişi” adlı metnin çalışma öncesindeki "Uğur Böceğim" adlı metinle karşılaştırılması sonucunda elde edilen öğrencinin ön okuma ve son okumasına ilişkin genel bilgiler olarak aşağıda verilmiştir:

Tablo 4: Öğrencinin Ön Okuma ve Son Okumasına İlişkin Genel Bilgiler

\begin{tabular}{cccccccc}
\hline $\begin{array}{c}\text { Metin } \\
\text { Düzeyi }\end{array}$ & Metin Adı & $\begin{array}{c}\text { Yapılan } \\
\text { Test }\end{array}$ & $\begin{array}{c}\text { Kelime } \\
\text { Sayısı }\end{array}$ & $\begin{array}{c}\text { Okuma } \\
\text { Süresi }\end{array}$ & $\begin{array}{c}\text { Hata } \\
\text { Sayısı }\end{array}$ & $\begin{array}{c}\text { Kelime } \\
\text { Tanıma } \\
\text { Yüzdesi }\end{array}$ & $\begin{array}{c}\text { Okuma } \\
\text { Düzeyi }\end{array}$ \\
\hline \multirow{2}{*}{2. sınıf } & $\begin{array}{c}\text { Uğur } \\
\text { Böceğim }\end{array}$ & Ön test & 156 & $11 \mathrm{dk} \mathrm{19} \mathrm{sn.}$ & 20 & $\% 90$ & $\begin{array}{c}\text { Endişe } \\
\text { Düzeyi }\end{array}$ \\
\cline { 2 - 7 } & $\begin{array}{c}\text { Selim'in } \\
\text { Çürük Dişi }\end{array}$ & Son test & 163 & $3 \mathrm{dk} .48 \mathrm{sn}$. & 8 & $\% 96$ & $\begin{array}{c}\text { Öğretim } \\
\text { Düzeyi }\end{array}$ \\
\hline
\end{tabular}

Yukarıdaki tabloda görüldüğü gibi çalışmanın sonunda öğrencinin hem okuma süresinde hem okuma sırasında yaptığı hata sayısında hem de kelime tanımada gözle görülür oranda gelişme olmuştur.

\section{Sonuç ve Tartışma}

Disleksi tanısı alan bir ilkokul üçüncü sınıf öğrencisinin okuma güçlüğünün giderilmesinde müziksel-ritmik müdahalelerin etkililiğini tespit etmeye yönelik bir çalışma gerçekleştirilmiştir. Müzik eğitimi öncesinde öğrencinin sıklıkla yaptığı hataları belirleyebilmek için milli eğitimin Türkçe ders kitaplarından alınan okuma parçalarından okumalar yaptırılmıştır. Öğrencinin kelime tanıma ve okuduğu metni anlama düzeyini ölçmek için "Yanlış Analizi Envanteri” kullanılmıştır. Daha sonra literatürde disleksiyi açıklamaya yönelik yaklaşımlar ve müdahale yöntemleri araştırılarak, öğrenci için nasıl bir müdahale programı hazırlanması gerektiği araştırılmış ve müzik eğitimi programı uygulanmasına karar verilmiştir. Müdahale programı boyunca, araştırmacılar etkinlikleri öğrenci ile birlikte birebir yürütmüş ve süreç boyunca öğrenciyi yakından izlemişlerdir. Uygulanan müzik eğitim programında şarkı metinlerinin tekrarlı ve eşli okunması öğrencinin hem okuma hatalarının azalmasında hem de okuduğunu anlama düzeyinin artmasında etkili olmuştur. 
Eğitimin başında çok yavaş ve hatalı okumalar yapan öğrenci, 156 kelimeden oluşan bir okuma parçasını eğitimden önce 11 dakika 19 saniyede okumuş ve bu okuma sırasında 20 hata yapmıştır. Öğrenciye uygulanan 24 saatlik müzik eğitiminin sonunda ise; öğrenci 163 kelimeden oluşan bir okuma parçasını 3 dakika 48 saniyede okumuş ve bu okuma sırasında 8 hata yapmıştır. Öğrencinin müzik eğitimi sonunda kelime tanıma ve okuduğunu anlama becerisinde artış görülmüştür. Yanlış Analizi Envanteri sonuçlarına göre müzik eğitiminden öğrencinin önce kelime tanıma ve okuduğu metni anlama düzeyi "Endişe Düzeyi”"nde yer alırken, müzik eğitimi sonunda kelime tanıma ve okuduğubir metni anlama düzeyi “Öğretim Düzeyi”ne çıkmıştır.

Ayrıca öğrencinin öğretmenleriyle, ailesiyle ve akranlarıyla yapılan görüşmeler sonucunda çalışmanın başında gözlenen çekingen ve içe kapanık tutumlarının eğitim sonunda azaldığı görülmüş ve bu verilerin araştırmacı günlüklerinde gözlemlenip eklendiği görülmektedir. elde edilen bir diğer gözlem sonuçları ise, öğrencinin okul bahçesi ve sınıf içinde arkadaşlarına ve öğretmenlerine karşı kendini daha iyi ifade edebildiği, öğrencinin özgüven ve benlik algısında iyileşmeler olduğu öğretmenleri, ailesi ve akranları tarafindan da fark edilmiştir.

Okuma hem eğitim alanında hem de hayatın her alanında oldukça gerekli bir alandır. Bunun için okumada yaşanacak güçlükler sadece akademik alanda değil, hayatın her alanında geri kalmaya sebep olacaktır. $\mathrm{Bu}$ nedenle okuma sürecinde yaşanan sorunlara erken müdahale edilmesi gerekmektedir.

Okuma güçlügüün̈n giderilmesinde alan yazını incelendiğinde farklı araştırmacılar tarafından yürütülen çeşitli tekniklere rastlanmaktadır. Yöntem seçimi için öğrencinin bireysel özellikleri dikkate alınmalı, bu doğrultuda öğrencinin özellikleri ve ihtiyaçlarına göre Bireyselleştirilmiş Eğitim Programı (BEP) oluşturulmalıdır. Özel Eğitim Hizmetleri Yönetmeliğine göre BEP "özel ĕgitim gerektiren birey için geliştirilen ve ailesi tarafindan onaylanan bireyselleştirilmiş eğitim programı, bireyin, ailenin, öğretmenin gereksinimleri doğrultusunda hazırlanan ve hedeflenen amaçlarda verilecek destek eğitim hizmetlerini içeren özel eğitim programı" olarak tanımlanmaktadır (MEB, 2000). Öğrencinin akademik alanda okuma güçlügü ve sosyal alanda özgüven eksikliği ile benlik algısının düşük olması neticesinde akademik ve sosyal alandaki ihtiyaçları göz önünde bulundurularak ilgi, istek ve becerileri doğrultusunda belirlenen müzik eğitimi programı hazırlanmıştır.

Okuma güçlüklerinin giderilmesine yönelik yapılan çalışmalar genellikle sınıfın dışında ve sınıftaki diğer çocuklardan ayrı bir şekilde birebir yürütüldüğünden bazı riskleri de beraberinde getirmektedir. (Reid, 2003). Çünkü çalışma sonunda öğrencinin okuma düzeynin yükselmesinde birebir ilginin mi, yoksa uygulanan yöntemin mi etkili olduğu sorusunu akla getirmektedir. Ancak müzik eğitim programının uygulandığı bu çalışmaya ve buna benzer olarak disleksinin müzik ile giderildiği çalışmalara bakıldığında sınıf içinde ve akranlarla uygulanmaya müsait bir uygulama olduğu görülmektedir. Okuma güçlüğünün giderilmesinde müzik eğitiminin etkisi konusunda sınıf öğretmenleri veya müzik öğretmenleri bilinçlendirilebilmesi etkili olacaktır. Hem okuma güçlüğü olmayan hem de okuma güçlüğü olan çocukların bir arada bulunduğu müzik derslerinde seslendirilen şarkı metinlerinin takip edilmesi sağlanarak eşli okuma, tekrarlı okuma gibi akıcı okuma tekniklerinin kullanılmasına olanak sağlanmış olacak; böylece müdahale planının diğer çocuklardan izole bir şekilde yürütülmesinin önüne geçilecektir.

Diğer önemli bir konu ise öğrencinin okumaya yönelik isteğidir. Öğrencinin okurken çok fazla güçlük çekmesi ve okuma konusunda akranlarından geri kalması okuma konusundaki motivasyonunu azaltır. Yapılan çalışmalarda okumaya karşı motivasyonu yüksek olan çocukların daha sık kitap okudukları ve bunun sonunda akıcı okuma becerisi kazandıkları tespit edilmiştir(Wang ve Guthrie, 2004). Bu çalışmada öğrencinin ilgi, istek ve becerileri de dikkate alınarak yürütüldüğünden şarkı metinlerini seslendirmeye yönelik olan motivasyonu eğitim süreci sonunda normal metinlere de genellenebilir bir motivasyona dönüşmüştür. Öğrencinin müziksel-ritmik 
okuma müdahalesi sonunda okumaya karşı motivasyonunun arttığı, dolayısıyla okuma eğiliminin yükseldiği gözlemlenmiştir. Okuma hataları azalan öğrenci daha akıcı okumaya başladığından, okuduğu metni anlama düzeyinin de arttığı görülmüştür.

\section{Kaynakça}

Akyol, H. (2011). Türkçe öğretim yöntemleri. (4. bs). Pegem.

Akyol, H. ve Yıldız, M. (2010). Okuma bozukluğu olan bir öğrencinin okuma ve yazma becerisinin geliştirilmesine yönelik bir durum çalışması. New World Sciences Academy, 5(4), 16901700.

Sezgin, Z. Ç., \& Akyol, H. (2015). Okuma güçlügü̈ olan dördüncü sınıf öğrencisinin okuma becerilerinin geliştirilmesi. Turkish Journal of Education, 4(2), 4-16.

Amerikan Psikiyatri Birliği (APA). (1994). Mental bozuklukların tanımsal ve sayısal el kitabı (DSMIV). (E. Köroğlu, Çev.). Ankara: Hekimler Yayın Birliği.

Baddeley, A. D. (1992). Working memory. Science, 255, 556- 559.

Başkale, H. (2016). Nitel araştırmalarda geçerlik, güvenirlik ve örneklem büyüklüğünün belirlenmesi. Dokuz Eylül Üniversitesi Hemşirelik Fakültesi Elektronik Dergisi, 9(1), 23-28

Brady, S., Shankweiler, D., \& Mann, V. (1983). Speech perception and memory coding in relation to reading ability. Journal of experimental child psychology, 35(2), 345-367. https://doi.org/10.1016/0022-0965(83)90087-5

Coltheart, M. (2005). Comprehension instruction: Research-based best practices. (Ed: Margaret J. Snowling and Charles Hulme). The Science of Reading: A Handbook. Blackwell.

Couture, A. E. ve McCauley, R. J. (2000). Phonological working memory in children with phonological impairment. Clinical Linguistics \& Phonetics, 14(7), 499-517. https://doi.org/10.1080/026992000750020332

Corrigall, K. A., \& Trainor, L. J. (2011). Associations between length of music training and reading skills in children. Music Perception: An Interdisciplinary Journal, 29(2), 147-155. https://doi.org/10.1525/mp.2011.29.2.147

Creswell, J. W. (2012). Educational research: Planning, conducting and evaluating quantitative and qualitative research. MA: Pearson

Creswell, J. W. (2015). Nitel araştırma yöntemleri: Beş yaklaşıma göre araştırma ve araştırma deseni (M. Bütün ve S. B. Demir, Çev.). Siyasal Kitabevi.

Ekwall, E. E. ve Shanker, J. L. (1988). Diagnosis and remediation of the disabled reader (3. bs.). Allyn and Bacon Inc.

Erden, G., Kurdoğlu, F. ve Uslu, R. (2002). İlköğretim okullarına devam eden Türk çocuklarının sınıf düzeylerine göre okuma hızı ve yazım hatalarının normlarının geliştirilmesi. Türk Psikiyatri Dergisi, 13(1), 5-13.

Flaugnacco, E., Lopez, L., Terribili, C., Montico, M., Zoia, S., \& Schön, D. (2015). Music training increases phonological awareness and reading skills in developmental dyslexia: a randomized control trial. PloS one, 10(9), e0138715. https://doi.org/10.1371/journal.pone.0138715

Gathercole, S. E. (2006). Nonword repetition and word learning: The nature of the relationship. Applied Psycholinguistics, 27, 513-543. https://doi.org/10.1017/s0142716406060383 
Gathercole, S. E. ve Baddeley, A. D. (1990). Phonological memory defi cits in language disordered children: Is there a causal connection? Journal of Memory and Language, 29, 336-360. https://doi.org/10.1016/0749-596x(90)90004-j

Guba, E. G. ve Lincoln, Y. S. (1982). Epistemological and methodological bases of naturalistic inquiry. Educational Communication and Technology Journal, 30(4), 233-252. https://link.springer.com/content/pdf/10.1007\%2FBF02765185 adresinden erişildi.

Guthrie, J. T., Wigfield, A. Metsala, J. L. and Cox, K. E. (1999). Motivational and cognitive predictors of text comprehension and reading amount. Scientific Studies of Reading, 5(3), 231-256. https://doi.org/10.1207/s1532799xssr0303_3

Güneş, F. (2007). Türkçe öğretimi ve zihinsel yapılandırma. Ankara: Nobel.

Habib, M., Lardy, C., Desiles, T., Commeiras, C., Chobert, J., \& Besson, M. (2016). Music and dyslexia: a new musical training method to improve reading and related disorders. Frontiers in psychology, 7, 26. https://doi.org/10.3389/fpsyg.2016.00026

Huss, M., Verney, J. P., Fosker, T., Mead, N., \& Goswami, U. (2011). Music, rhythm, rise time perception and developmental dyslexia: perception of musical meter predicts reading and phonology. Cortex, 47(6), 674-689. https://doi.org/10.1016/j.cortex.2010.07.010

Karaman, D., Kara, K., \& Durukan, İ. (2012). Özgül Öğrenme Bozukluğu. Anatolian Journal of Clinical Investigation, 6(4).

Korkmazlar, Ü. (1994). Özel öğrenme bozukluğu. Taç Ofset

Kurdoğlu. F. (2005). Özgül öğrenme bozukluğu'nda tanı değerlendirme. Dikkat eksikliği ve hiperaktivite bozukluğu ve özgül öğrenme güçlüğü içinde (43-55). Ankara Üniversitesi Basım Evi.

Levine, M. (2005). Her çocuk başarabilir, okul çağında zihinsel gelişim ve öğrenme farklılıkları. (Z. Babayiğit, Çev.). İstanbul: Boyner Yayınları

O'Brien, R. (2003). An Overview of the Methodological Approach of Action Research. (Online). http://www.web.ca/ robrien/papers/arfinal.html

Overy, K. (2003). Dyslexia and music: From timing deficits to musical intervention. Annals of the New York Academy of Sciences, 999(1), 497-505. https://doi.org/10.1196/annals.1284.060

Özyürek, I. ve Özsoy, A. (1991). Öğrenme güçlüğü (1. bask1). T.C. Milli Eğitim Bakanlığı Özel Eğitim ve Rehberlik Dairesi Başkanlığı.

Milli Eğitim Bakanlığı (2000). Özel eğitim hakkında kanun hükmünde kararname ve özel eğitim hizmetleri yönetmeliği. Milli Eğitim Basımevi.

Moreno, S., Marques, C., Santos, A., Santos, M., Castro, S. L., \& Besson, M. (2008). Musical training influences linguistic abilities in 8-year-old children: more evidence for brain plasticity. Cerebral Cortex, 19(3), 712-723. https://doi.org/10.1093/cercor/bhn120

Poblano, A., Tepec, T. V., Arias, M. L. ve Pedroza, F. G. (2001). Phonological and visuo-spatial working memory alterations in dyslexic children. Archives of Medical Research, 31, 493496. https://doi.org/10.1016/s0188-4409(00)00096-5

Punch, K. F. (2005). Sosyal araştırmalara giriş- nicel ve nitel yaklaşımlar. Siyasal Kitabevi.

Razon, N. (1976). Özel bir okuma bozukluğu (1. baskı). İstanbul Üniversitesi Edebiyat Fakültesi Yayınları.

Reid, G. (2003) Dyslexia: A practitioner's handbook. (3th ed.). Wiley 
Savaşır, I. ve Şahin, N. (1995). Wechsler Çocuklar için Zeka Ölçeği (WISC-R). Türk Psikologlar Derneği.

Sever, S. (2004). Türkçe öğretimi ve tam öğrenme. Anı.

Tallal, P., \& Gaab, N. (2006). Dynamic auditory processing, musical experience and language development. Trends in neurosciences, 29(7), 382-390. https://doi.org/10.1016/j.tins.2006.06.003

Snowling, M. J. (1981). Phonemic deficits in developmental dyslexia. Psychological research, 43(2), 219-234. https://doi.org/10.1007/bf00309831

Snowling, M., Goulandris N., Bowlby M. ve Howel P. (1986). Segmentation and speech perception in relation to reading skill: A developmental analysis. Journal of Experimental Child Psychology, 41, 489-507. https://doi.org/10.1016/0022-0965(86)90006-8

Teele, S. (1997). The multiple intelligences school. Redlands CA: Citrograph Printing

Tracey, D. H. and Morrow, L. M. (2006). Lenses on reading. The Guilford.

Vanlı, L. (1988). Dislektik çocuklarda algısal bozukluklar ve okuma-yazma hataları. Türk Psikoloji Dergisi, 6(22), 36- 40.

Wang, J. H. and Guthrie, J. T. (2004). Modeling the effecets of intrinsic motivation, extrinsic motivation, amount of reading, and past reading achievement on text comprehensionn between U.S. and Chinese students. Reading Research Quaterly, 39, 162-186. https://doi.org/10.1598/rrq.39.2.2

World Federation of Neurology (1968). Report of research group on dyslexia and world illiteracy. Dallas, TX: WFN.

Yalın, A. ve Karakaş, S. (1994). Görsel İşitsel Sayı Dizisi Testi A formunun bir Türk çocuk örnekleminde güvenirlik, geçerlik ve standardizasyon çalışması. Türk Psikoloji Dergisi, 9(32), 6-14.

Yıldırım, A., \& Şimşek, H. (2011). Sosyal bilimlerde nitel araştırma yöntemleri. Ankara: Seçkin Kitabevi. 